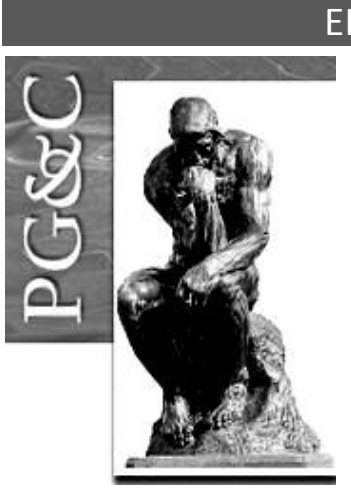

\title{
PERSPECTIVAS EM GESTÃO \& CONHECIMENTO: COMPARTILHANDO AS PARCERIAS
} Perspectivas em Gestão \& Conhecimento (PG\&C) no I Workshop do Grupo de Pesquisa Gestão da Informação e do Conhecimento (GIACO) vinculado ao Programa de Pós-Graduação em Ciência da Informação da Universidade Federal da Paraíba (PPGCI/UFPB). A PG\&C marcou presença no evento para compartilhar as importantes parcerias que a revista já firmou ao longo dos seus oito anos de existência.

O Workshop em referência teve lugar na UFPB no dia 11 de julho de 2018. Dentre as comunicações, destacamos a apresentação do Programa de Pós-Graduação em Gestão da Informação e do Conhecimento da Universidade Federal do Rio Grande Norte que oferta curso de mestrado profissional, a apresentação de pesquisas de iniciação científica acerca da Gestão da Informação e do Conhecimento, os produtos científicos do GIACO e, por fim, a apresentação das parcerias da PG\&C.

$\mathrm{Na}$ oportunidade, impossível não evidenciar as parcerias com reconhecidos eventos das mais diversas áreas de conhecimento, a exemplo do 5 ㅇ Encontro Brasileiro de Arquitetura da Informação (Edição denominada Perspectivas em Arquitetura da Informação), do Encontro Nacional de Pesquisa e Pós-Graduação em Ciência da Informação, especificamente com o Grupo de Trabalho 4 - Gestão da Informação e do Conhecimento (edição denominada Gestão da Informação e do Conhecimento no âmbito da Ciência da Informação), do KM Brasil - Congresso Brasileiro de Gestão do Conhecimento (Edição denominada Gestão do Conhecimento, Eficiência e Inovação em 2017). Aliás, com este último evento, a parceria para 2018 já foi firmada. Mencionamos, ainda, a parceria com o com o Simpósio Internacional de Gestão de Projetos, Inovação e Sustentabilidade. E temos mais demandas de parcerias!

Encerradas estas breves considerações, em cumprimento à nova periodicidade da PG\&C - quadrimestral - apresentamos o volume 8, número 2, maio/ago. 2018, em que trazemos 10 Relatos de Pesquisa e uma Entrevista, além dos clássicos Editorial e Expediente.

A seção Relatos de Pesquisa é iniciada pelo artigo intitulado Fatores facilitadores da aprendizagem organizacional para a criação de significado em instituições de ensino superior privadas de Curitiba e região metropolitana, de autoria de Francisca Mary Magalhães de Alcântara e Helena de Fátima Nunes Silva, que se propôs a identificar se os gestores das instituições de ensino superior privado da região metropolitana de Curitiba percebem a existência dos fatores facilitadores da aprendizagem organizacional em seu ambiente de trabalho.

O segundo Relato de Pesquisa intitulado Ambientes determinantes ao compartilhamento do conhecimento em organizações de radiologia e diagnóstico por imagem: um estudo de casos múltiplos é de autoria de Patrícia Fernanda Dorow, Mirian Magnus Machado, Andressa Gonçalves e Vanessa Zucki Machado. No relato os autores investigaram a estrutura ambiental de três organizações de radiologia e

Perspectivas em Gestão \& Conhecimento, João Pessoa, v. 8, n. 2, p. 1-3, mai./ago. 2018. DOI: http://dx.doi.org/10.21714/2236-417X2018v8n2p1

http://periodicos.ufpb.br/ojs2/index.php/pgc. ISSN: 2236-417X. Publicação sob Licença (cc) EY-NC-ND. 
diagnóstico por imagem, por considerarem as organizações em referência como intensivas em conhecimento, já que o tipo de atividade realizada é altamente cognitiva.

Em seguida, o terceiro Relato de Pesquisa dos autores Fabrício Burger, Rodrigo Kraemer, Gertrudes Aparecida Dandolini, João Artur de Souza e Patrícia de Sá Freire, sob o título de Barreiras, elementos dificultadores e fatores críticos na implementação da gestão do conhecimento: uma revisão da literatura, considerando as barreiras na implementação de gestão do conhecimento como base para a construção de mecanismos de superação antes mesmo da implementação em si da gestão do conhecimento, objetiva identificar as barreiras à implementação do processo de gestão do conhecimento.

O Relato de Pesquisa O papel da comunicação na gestão do conhecimento: aspectos relevantes e estímulo a novas pesquisas, de autoria de Ângela Pizzaia, Paulo Marcelo Ferraresi Pegino, Júlio Ernesto Colla e Nelson Nunes Tenório Júnior, propõe-se a discutir os aspectos importantes da comunicação, geralmente um aspecto negligenciado, nos modelos da gestão do conhecimento no sentido de refletir o papel da comunicação nesses modelos.

Em seguida, o quinto Relato de Pesquisa de autoria de Roberta Rodrigues Faoro, Chariel Simioni de Oliveira e Marcelo Faoro de Abreu, intitulado Compartilhamento do conhecimento na cadeia produtiva dos pequenos frutos, busca analisar como acontece o compartilhamento do conhecimento entre integrantes da cadeia produtiva - fornecedores de insumos, produtores, agroindústria, comércio no atacado, comércio varejista e consumidores - na região dos Campos de Cima da Serra localizada no Rio Grande do Sul.

Grupos de pesquisa: dinâmica do compartilhamento de conhecimento, dos autores Alice Munz Fernandes, Rejane Remussi, Fernanda Pauletto D'Arrigo e Ana Cristina Fachinelli, é o sexto Relato de Pesquisa. Tem por objetivo examinar a dinâmica do compartilhamento de conhecimento - identificado como uma das principais áreas da gestão do conhecimento - nos Núcleos de Pesquisa e Núcleos de Inovação e Desenvolvimento de uma instituição de ensino superior localizada na Serra Gaúcha.

O Relato de Pesquisa sequente sob o título de Redes sociais e recursos em empresas de base tecnológica: um estudo exploratório, dos autores Mário Sacomano Neto e Gabriela Locachevic, analisa as redes, no que diz respeito a sua estrutura, nós, ligações e fluxos, e identifica quais são os recursos compartilhados nas relações de empresas pertencentes ao Centro Incubador de Empresas de Software (Softnet).

O oitavo Relato de Pesquisa, Redes de colaboração das empresas de software: estudo das práticas de inovação aberta da autora Ana Clara Cândido, visa identificar as práticas de inovação aberta adotadas por empresas brasileiras de software, reconhecido como um setor que tem forte representatividade na economia brasileira.

Em $A$ efetividade informacional dos portais de transparência governamentais na perspectiva do cidadão, o autor Maciel Carlos Antunes se propõe a verificar se os dados postados nos portais de transparência atendem às preferências dos cidadãos e despertam nestes o interesse em participar das decisões políticas.

O último Relato de Pesquisa é de autoria do André Luiz Barbosa Silva, sob o título Experiência didática na aplicabilidade e estruturação da Aprendizagem Baseada em Problemas (ABP): percepções dos alunos do Curso de Administração $e$ 
recomendações para implementação, propõe-se a demostrar como estruturar e aplicar o método da Aprendizagem Baseada em Problemas em uma disciplina do curso de Administração como estratégia de metodologia ativa.

Por fim, nesta Edição, nós editores da PG\&C temos a satisfação de apresentar a entrevista que nos concedeu a Professora Emeide Nóbrega Duarte do Departamento de Ciência da Informação da Universidade Federal da Paraíba, com atuação junto ao PPGCI/UFPB na condição de docente do núcleo permanente do programa. Para além disso, a docente/pesquisadora é líder do GIACO e detentora de vasta produção científica acerca da Gestão da Informação e do Conhecimento. A entrevista nos traz reflexões sobre a trajetória acadêmico-científica da docente/pesquisadora e sua perspectiva sobre os estudos de Gestão da Informação e do Conhecimento.

Feita a apresentação do conteúdo que compõe a atual edição, agradecemos ao Comitê Editorial, ao Conselho Consultivo, aos Avaliadores, aos autores e aos nossos leitores. Agradecemos pela confiança no trabalho da PG\&C.

Fica o convite para acessar os itens de interesse para proveitosa leitura, bem como para seguir a PG\&C no Twitter.

Excelente leitura a todos!

João Pessoa, Paraíba, Brasil, 29 de Agosto de 2018.

Os Editores

Jorge de Oliveira Gomes e Luciana Ferreira da Costa

https://twitter.com/revistapgecufpb 